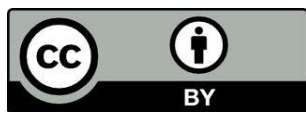

\title{
AS BENZEDEIRAS TRADICIONAIS DE CURITIBA: IDENTIFICAÇÃO E ANÁLISES
}

\author{
The Traditional Healers Curitiba: Identification And Analyses
}

Victor Augustus Graciotto Silva

Mestre em História pela Universidade Federal do Paraná em 2005. Editor e gestor cultural da Máquina de Escrever Editora e Produtora Cultural. Atualmente pesquisa sobre temas de patrimônio cultural e histórico de Curitiba. Contato: victoraugustus@yahoo.com.br

RESUMO: Este trabalho registra a presença nos dias de hoje de um grupo social reconhecido pelo poder de curar através de práticas de medicina popular. Diante do mundo moderno, em especial da medicina erudita, que dia após dia apresenta inovações tecnológicas, encontramos pessoas que crêem na eficácia das tradicionais benzedeiras para curar doenças. Dialogando com os temas da religiosidade popular, da história da saúde e do patrimônio cultural imaterial, o presente artigo objetiva mostrar os caminhos da pesquisa desenvolvida sobre as práticas culturais das benzedeiras tradicionais de Curitiba nesta primeira década do século XXI.

Palavras Chave: benzedeira; patrimônio cultural imaterial; religiosidade popular; Curitiba.

ASTRACT: This paper reports the presence today of a social group recognized the power of healing through practices of folk medicine. Before the modern world, especially medicine erudite, who day after day presents technological innovations, we find people who believe in the effectiveness of traditional healers to cure diseases. In dialogue with the themes of popular religiosity, health history and of intangible cultural heritage, this article aims to show the ways the research developed on the cultural practices of traditional healers in Curitiba in this first decade of this century XXI.

Keywords: healer; intangible cultural heritage; popular religiosity; Curitiba. 
A prefeitura de Curitiba apresenta em sua política de valorização da cultura imaterial do município, desde 2006, o edital para Identificação e Registro do Patrimônio Imaterial. Na edição de 2008, inscrevemos o projeto BENZA DEUS! Benzedeiras de Curitiba: modernidade e tradição, que foi selecionado. Este projeto identificou e registrou as Benzedeiras Tradicionais de Curitiba como Patrimônio Cultural Imaterial.

Realizou uma ampla pesquisa de campo em Curitiba, estendendo-se em todas as regionais, identificando e mapeando as benzedeiras tradicionais em atividade. Optouse, como critério para identifica-las, aquelas que eram reconhecidas pela comunidade como benzedeiras e que não cobravam pelo benzimento. Com início em Dezembro de 2008 e término em Novembro de 2009, foi elaborado três produtos: um livro digital contendo a identificação das benzedeiras; um livro digital contendo as histórias de vida de algumas delas; e por fim, um conjunto de painéis apresentando uma síntese dos produtos obtidos, voltado para exposições itinerantes.

Ao concluir em 2009 a pesquisa de identificação e registro das benzedeiras tradicionais como patrimônio cultural imaterial de Curitiba, os dados obtidos levaram a questionamentos que extrapolavam os objetivos e os limites daquela pesquisa.

A história das benzedeiras, permeadas de perseguições, preconceitos, aceitações, reconhecimentos, pobreza, religião e crença, que ao serem contextualizadas com o processo de urbanização e industrialização de Curitiba e com as imigrações e migrações decorrentes de tal processo, explicitam interações entre a cultura do campo e a cultura da cidade, da mão-de-obra migrante e da elite urbana, da medicina popular e da medicina erudita, da religiosidade popular e da religião institucionalizada, constituindo um processo dinâmico e complexo de trocas culturais.

Compreender as benzedeiras e sua prática de cura é buscar o significado de sua prática social, entendendo como é recriada essa cultura popular. Significa explicitar, a partir de relações sociais definidas, uma visão de mundo, da benzedeira com aqueles que a procuram, com o seu ofício de benzer, com a sua vida cotidiana. O próprio ato de benzer sintetiza momento concreto do confronto entre o popular e o erudito, em que a benzedeira antagoniza o seu conhecimento ao dos padres e médicos, propõe uma 
releitura da religião e da medicina, se faz existir enquanto sujeito. A resistência cultural se expressa pela eficácia desse ato de benzer e nos remete àqueles que sustentam tal eficácia, os que acreditam nela, os que a procuram. A eficácia simbólica das benzedeiras não acontece somente na eliminação dos males, acontece quando elas envolvem as pessoas e problemas produzidos dentro dessa cultura popular, revitalizando-a, recriando-a.

Muitas vezes cunhadas como feiticeiras, outras como curandeiras, o que define as benzedeiras é a crença em sua arte de cura pela reza, sinal da cruz e ervas. Como objeto de estudo, o universo acadêmico situa as benzedeiras como médicas populares. As leituras do fenômeno da benzeção respondem a olhares que percorrem, desde o campo médico-científico, até os trabalhos das ciências sociais e humanas - sociologia, antropologia e história -, em que um leque de abordagens e estudos se abre centrando na questão da religiosidade popular.

Dialogando com essas duas grandes linhas de análise sobre as benzedeiras, propomos centrar nossa discussão em um ponto nerval: a compreensão das benzedeiras enquanto resistência política e cultural na cidade.

E é nesse contexto de trocas sociais mais amplas que essa população subalterna afirma sua identidade de pobre, oprimida, desenraizada e expropriada do saber científico sobre o corpo e as funções vitais. É no próprio modo de produzir as suas medicinas populares que essa população resiste política e culturalmente a opressão imposta pelas classes dominantes. Através da sua vida e dos modos que esta população encontra para lidar com suas doenças é que afirmamos que não há uma única medicina popular. Mas várias, e, em constantes transformações. E através delas dá-se uma das maneiras possíveis desta população explicar o modo como vivem: o modo como é politicamente marginalizada e economicamente expropriada nesta sociedade. O modo como está concretamente inserida nas relações sociais mais amplas. (OLIVEIRA, 1984, p. 38) 
É o que nos diz também Zélia Lopes da Silva:

O estudo de temas que envolvem a cura e os sujeitos habilitados para o seu exercício [...] carrega em seu âmago disputas significativas travadas ao longo dos séculos sobre os poderes daqueles que detinham conhecimentos no trato dos males do corpo (e da alma) dos homens. Quase sempre marcadas por paixões e violências, essas querelas perpassaram espaços sociais diferenciados, considerando-se que a primazia desses conhecimentos nem sempre esteve circunscrita às elites. A consequiência é, igualmente, a demarcação de campos polares e percepção desses saberes, fissura que propiciou a emergência dos diversos estigmas aos conhecimentos populares sobre as doenças e, também, aos seus divulgadores, classificados ora e "bruxos/bruxas", ora de "curandeiros", perseguidos ou tolerados, conforme as conveniências momentâneas dessas elites. (CARVALHO, 2005, p. 11)

Documentos impressos da primeira metade do século $\mathrm{XX}$ e fontes orais de benzedeiras desse início do século XXI, acabaram por explicitar as benzedeiras como um ato de resistência política e cultural, através de uma cultura que não é apenas uma maneira própria delas lerem o mundo, mas uma cultura que contesta e rejeita o discurso opressivo do dominante. As benzedeiras e suas práticas de cura exprimem uma identidade constituída em uma relação de afetividade e solidariedade entre os grupos sociais dessa cultura popular. O falar de, sobre e para a cultura popular, e contra a cultura erudita, emerge entre as palavras muitas vezes de forma direta, clara, profunda e irreverente.

Em relação a discussão entre cultura popular e cultura erudita, entendemos que a cultura é elemento fundamental na constituição da ordem social e que pode ser investigada como um sistema de significações de modo a permitir a inclusão de todas as práticas e definir-se como um processo social constitutivo que cria diferentes e 
específicos modos de vida (FENELON, 1993, p. 80). Nesse sentido, a cultura popular não se apresenta como completa, autêntica, autônoma e inteiramente unida a classes inteiras, mesmo considerando que há formações classistas culturais definidas e variáveis (HALL, 1984, p. 95).

Edward THOMPSON, ao estudar a questão dos usos e costumes na Inglaterra do século XVIIII, alerta que é necessário ter cuidados ao utilizar generalizações como cultura popular, pois “o próprio termo 'cultura', com sua invocação confortável de um consenso, pode distrair nossa atenção das contradições culturais, das fraturas e oposições existentes dentro do conjunto"; assim, generalizar a cultura popular somente é possível se colocá-la "firmemente dentro de contextos históricos específicos" e "situada no lugar material que lhe corresponde" (1998, p. 17).

Seguindo a afirmação de Roger CHARTIER (1990, p. 105) do problema em se estabelecer uma oposição evidente entre cultura popular e cultura de elite, Laura de Mello e SOUZA (1986; 1993), ao estudar as práticas de feitiçaria nos séculos XVI ao XVIII, confirma que não há, realmente, uma oposição clara entre cultura popular e de elite, pelo contrário, existe uma grande proximidade.

Por fim, Carlo GINZBURG $(1987 ; 1988 ; 1991)$, ao estudar a cultura popular européia na Idade Média e na Idade Moderna, identifica circularidades culturais entre a cultura folclórica e a cultura erudita e aponta como resultado desse conflito um hibridismo, as culturas se misturam e se modificam, em um movimento constante que, ao mesmo tempo, que incorporam novidades, apresentam estratos que não se modificaram. A essa cultura híbrida do encontro do folclórico e do erudito, GINZBURG (1991) conceitua como uma formação cultural de compromisso, uma cultura que vai se constituindo ao longo das interações; e um compromisso, indicativo da existência de mecanismos ideológicos orquestrados por agentes específicos, que revelam a relação de força existente entre os sujeitos.

Se Carlo Ginzburg responde a principal referência teórica para compreender a troca e a interação cultural, no que se refere a crença na benzedeira temos os estudos de LÉVI-STRAUSS (1985) a respeito da eficácia simbólica. Ele aponta para a importância da crença na magia para sua eficácia, mais do que quaisquer fatores objetivos. Nas palavras de MONTERO, “a magia funciona porque as pessoas crêem” (1986, p.61). Nessa mesma linha, que a eficácia existe quando sustentada por uma crença coletiva, 
temos também os trabalhos de Marcel MAUSS (1974). Ao trabalhar o maná, espécie de poder sagrado, coloca a idéia que o mágico é procurado porque se acredita de antemão nele. Concluindo, a crença se apresenta de forma complementar e interdependente: a crença do feiticeiro na eficácia de suas técnicas; a crença do enfermo no poder do feiticeiro; e a confiança e as exigências do grupo social (LÉVI-STRAUSS, 1985, p. 193-213). Temos ainda a pesquisa de Marc BLOCH (1993) sobre a cura das escrófulas através do toque régio. Ele analisa a crença nesse milagre tendo como pressuposto de que só existia o milagre porque se acreditava nele.

Sujeito de sua história, é dando voz as benzedeiras que podemos compreender a sua presença nos dias de hoje. A sua resistência política e cultural assume novo sentido ao ser encarada como parte do seu cotidiano ao longo dos anos. A partir das entrevistas realizadas com as benzedeiras iremos apresentar alguns dados que possibilitam visualizar um itinerário das benzedeiras, em que suas memórias nos levam aos anos de 1900, ao contexto daqueles benzedores que transmitiram ou possibilitaram a passagem do dom de benzer a elas. Depois, percorrem sua infância, juventude, casamento e deslocamentos até se fixarem em Curitiba, percurso onde ocorre a passagem do dom e o início das atividades de benzimento. Por fim, o ofício de benzer, com suas inúmeras histórias e casos até os dias de hoje.

Antes de trabalhar com as entrevistas, iremos expor algumas impressões sobre a pesquisa de campo, que de forma geral consistiu em identificar as benzedeiras tradicionais reconhecidas pela comunidade, com entrevista e registro fotográfico delas.

A primeira parte da pesquisa foi composta por leituras sobre o tema, um conjunto de textos que propiciou a construção do conhecimento sobre as formas de religiosidade brasileira e a produção do saber popular, no que tange aos benzimentos e seu significado cultural. A partir daí ficou estabelecido que os pesquisadores, divididos por setores, iriam buscar, junto às Unidades de Saúde, um contato com suas atendentes. Estas, por estarem em contato permanente com a população da área ou setor abarcado pela US à qual prestam serviços, poderiam bem informar sobre a existência de benzedeiras. Ao final da coleta de dados, teria sido mapeada cada área e/ou setor da 
cidade de Curitiba e o resultado chegaria muito perto do total de benzedeiras em ação na cidade.

Pelo roteiro inicial, o primeiro passo era entrar em contato com a Autoridade Sanitária da Unidade Básica de Saúde para saber quando era possível encontrar os agentes comunitários de saúde reunidos para pedir a informação: se eles conhecem benzedeiros no bairro e se podiam me passar o endereço. De início, as Autoridades Sanitárias foram solícitas e interessadas na pesquisa, embora solicitassem um documento de aprovação do Distrito Sanitário, posto de hierarquia maior que a Unidade Básica de Saúde. Isto chega ao Distrito Sanitário e a orientação que teve era a de que só poderia conversar com os agentes comunitários de saúde e pedir-lhes a informação com a autorização da Secretaria de Saúde de Curitiba.

Diante das dificuldades, a pesquisa procurou caminhos alternativos, que pretendiam correr paralelos à ideia inicial. Sendo assim, com o intento de buscar outros contatos, os de pessoas que frequentassem benzedeiras, uma rede de informações foi sendo construída, a partir da pergunta informal: "Você conhece alguma benzedeira?" Com a pesquisa de campo, junto a pessoas desconhecidas, tentando formar a rede de contatos, pudemos perceber um interesse significativo pelo tema a ser desenvolvido. De maneira geral, as informações, quando existiam, eram repassadas de maneira simples, clara, precisa, às vezes elaborando-se mapas explicativos para que se pudesse encontrar o endereço apontado - muito diferente do ambiente das US, onde ficávamos à espera para sermos atendidos, e saíamos sem nenhuma informação. Da mesma forma, as agentes de saúde quando contatadas na rua foram atenciosas, independente do fato de terem ou não nome/endereço a nos indicar.

No desenrolar do processo de pesquisa, optamos então por priorizar as informações advindas desta rede crescente de colaboradores, conferindo informações, catalogando endereços, anexando contatos. Conseguimos obter indicações de 87 benzedeiras. Destas, 61 foram entrevistadas. Doenças, mudança de endereço ou de telefone, informações desencontradas foram as causas principais desse hiato documental.

Detalhe importante, no contato com as benzedeiras, houve a preocupação, por parte das mulheres contatadas em não divulgar seus nomes e endereços, para não aumentar a procura, pois já atendiam muita gente e não haveria como "dar conta de uma 
demanda maior", e também para não fazer propaganda do seu ofício, ao que julgam incorreto.

Das 61 benzedeiras entrevistadas, a maioria nasceu no Paraná. Contudo, apenas 9 nasceram em Curitiba, e dessas, 5 são descendentes de imigrantes europeus que chegaram na cidade entre o final do século XIX e primeira metade do XX. Considerando aquelas que vieram do interior do Paraná e as dos outros estados - Santa Catarina, Rio Grande do Sul, São Paulo, Minas Gerais, Bahia e Pernambuco - temos que $80 \%$ delas tem sua vinda a Curitiba relacionada ao processo de urbanização e êxodo rural das décadas que vão de 1950 a 1970, o que também explica a grande concentração delas na região sul de Curitiba, principalmente nos bairros que foram povoados a partir da década de 1970, como da regional CIC e Boqueirão.

Cerca de $35 \%$ delas nasceram na década de 1930 , outros $25 \%$ na década de 1920, 20\% na década de 1940. A benzedeira com idade mais avançada nasceu em 1918, enquanto que a mais nova é de 1962.

Outra questão relevante é sobre a religião. Apesar do número expressivo de benzedeiras católicas, cerca de 80\%, temos também: espíritas kardecistas, espiritualistas, umbandistas e do candomblé. A esta presença de benzedeiras que não são católicas, soma-se aquelas que afirmam serem católicas, mas em seus altares tem-se a imagem de personalidades kardecistas, como também de orixás.

Dona Yara, benzedeira que mora no bairro Pinheirinho, é um exemplo característico da benzedeira tradicional de Curitiba. Sua mãe, filha de pai polonês e de mãe russa, nascera na Rússia. Veio para Curitiba quando ainda era bebê. Já seu pai, também falecido, foi criado em Minas Gerais. Ele perdera a mãe quando era bebê, e, aos 11 anos, foi atropelado e perdeu uma perna. Após o acidente veio para Curitiba com o pai, irmã e irmãos. Aqui conheceu sua esposa e, da união do casal nasceu Yara, dia 8 de dezembro de 1950, em Curitiba no bairro Uberaba.

Dona Yara viveu sua infância e juventude naquele bairro, somente saindo de lá após se casar. Sobre sua infância, sua memória percorre os caminhos do trabalho do pai. 
Que do tempo que eu era criança eu vinha, lá do Uberaba até a vila Hauer, a pé! Meu falecido pai tinha uma banca na vila Hauer, perto do cinema, e ele fazia um doce caseiro prá por na banca e eu vinha trazê. Vinha eu e meus dois irmão. Nóis passava por dentro daquele rio, o Rio Belém... Nem pela ponte, por dentro... Não era tão limpo, que a gente chegou a se cortá até com caco de vidro... Criança gosta de fazê bagunça né? [risos]... A minha infância foi uma infância boa. [Ficar na rua] Não, não, isso a mãe nunca deixou. A falecida mãe nunca deixava. Ela queria que a gente ficasse dentro de casa. Então brincava eu e meus dois irmãos. Onde nóis morava tinha mato. No meio do mato tinha estrada, [...] era, era, era... uma transmissora de rádio, antiga rádio Guairacá! O falecido pai trabalhava lá. Então eu brincava cum irmão meu, brincava de índio, fazia cabana... [risos] Aquele tempo é tempo gostoso.

A última vez que esteve no bairro, há três ou quatro anos atrás, visitando uma tia que lá reside, estranhou tantas mudanças.

Assim o que mudou bastante é que quando a gente era criança tinha mais liberdade do que hoje em dia, hoje em dia todas as criança não tem liberdade. Hoje em dia não dá pra dá liberdade, tem muita droga, muita criminalidade... Então não dá pra gente soltá uma criança que nem na época minha. Na minha época podia não tinha esses perigo que tem hoje em dia e ninguém faltava com o respeito, eu, quando comecei a namorá meu falecido marido, eu tinha 12 anos... brincava.

Dona Yara conheceu seu marido por intermédio da irmã dele, quando era ainda uma "meninota". Sua então futura cunhada viera de Santa Catarina para fazer um tratamento em Curitiba. Estava grávida. Aqui se estabeleceram, ela e o marido, que passou a trabalhar no Prosdócimo. Os irmãos também foram chegando, primeiro um, 
depois o outro. Todos morando na mesma casa. Por gostar muito de crianças, Dona Yara estava sempre por perto, queria cuidar da criança que estava para chegar. Estava com 12 anos. E, "antigamente os pais arrumavam casamento pros filho, né? E a falecida mãe conversou com ele e [...] a mãe disse que tinha uma menina lá em casa... daí foi aonde eu comecei a namorá."

A diferença de idade entre os dois, quatorze ou quinze anos, seria incomum para a época, segundo Dona Yara, embora não tivesse representado algum tipo de impedimento ao casamento.

Seu ofício de benzedeira começou quando já estava casada e morava no bairro Pinheirinho. Uma vizinha, agora sua comadre, tinha uma criança que estava doente e os médicos não conseguiam curar. Estava entre a vida e a morte.

Ela tava mais pra morrê do que pra vivê. Daí, eu sou espírita, daí meu marido falou pra mim: "Vê se você consegue fazê alguma coisa por aquela criança, aquela criança vai morrê.” E eu olhei assim na criança, a criança tava só corinho e osso. Eu olhei e disse ah, vou dá uma medida nessa criança. Assim de cabeça, a medida veio na minha cabeça. Foi o que eu fiz, o benzimento, fiz com fio, fui cortando, as palavra que vinha na minha cabeça eu dizia e eu curei aquela criança, aquela criança ficou curada, e eu não parei mais.

Dona Yara afirma que o benzimento surgiu espontaneamente e que não tinha visto ninguém fazendo algo parecido antes. A partir desse dia, as pessoas começaram a aparecer e a recomendar a Dona Yara. Na época, morava em outra casa no mesmo bairro, o Pinheirinho. Há 34 anos, mudou-se para a casa atual e durante todo esse tempo benze a todos que ali batem à porta, sem cobrar pelo benzimento.

E não cobro porque eu nunca acreditei na pessoa que cobra. Eu acho que a pessoa que cobra, ela não tá fazendo o bem, ela tá fazendo dinheiro pra ela, que ela quer dinheiro. [Mas aceita contribuições]. Ah, daí eu aceito! [...] Mas cobrar eu não cobro! 
Tudo me pergunta: “Quanto você cobra?” Não, eu não cobro nada... Elas dão sempre presente. [...] Eles dão presente, às vezes trazem mantimento, essas coisas assim né...

Dona Yara conta sobre alguns benzimentos. Pessoas que ela acompanhou durante meses, que mandaram notícias anos depois de terem sido benzidas.

Tem um que eu curei quando era nenê, ele tinha uns problema muito grave o médico também não conseguia resolver. Passou anos, anos, daí uma vez encontrei ele lá no terminal do Boqueirão. Encontrei a mãe dele com um baita rapazão e nóis conversando ela falou assim: "Você lembra do meu filho?" Eu falei, lembro, daí ela me mostrou eu falei: ”Nossa! Como tá grande!"

Mas as veiz tem umas criança que os pai me dão foto, que eu fico olhando só a foto. Benzo se mora longe. [...] É, se tiver longe dá pra benzê por foto. [...] É uma bonequinha. Tô loca pra vê ela. A mãe dela, Rosa, me deu a foto pra mim guardá de lembrança da Giovana. Eu comecei a cuidá dela, agora ela tá com quase dois anos já. Eu comecei a cuidá dela tava com 14, 15 dias da dieta, quando Rosa trouxe ela pra mim, a Giovana. Ontem eu tava falando pra Cléia: "Saudade dessa Giovana! Queria tanto vê a Giovana!" Faz tempo que a gente não vê a Rosa, o nome da mãe dela é Rosa [...] [mostra a fotografia da Giovana] Essa é a Giovana. Ela tinha oito meses. E agora tá com quase dois anos. É. Acho que a Giovana já fez dois anos.

No rito da benzeção, a reza é o elemento central:

Eu rezo assim, como se diz, normal, mas sempre você tem um santo que você tem mais fé né? Então eu sempre faço minhas 
prece pro santo que eu tenho mais fé. Ah, eu tenho fé em Nossa Senhora Aparecida. É, tem Nossa Senhora Aparecida. E depende do benzimento de criança eu rezo pra Cosme e Damião, preto velho...

Dona Yara, filha de pais espíritas, é espírita desde pequena, mas, também foi batizada e crismada na Igreja católica. "Fui batizada, fui crismada, fiz primeira comunhão tudo. Sô batizada em terreiro também. [...] eu fui batizada nesse terreiro, tenho padrinho espiritual."

Sobre as doenças que benze, afirma: “Ah, eu benzo de tudo. [...] É, desde o começo. Doença de minguá, não dá nem pra fala o nome porque não presta né? Aquela doença de macaco que dizem. Benzo de míngua, benzo bicha, rasgadura, costuro rasgadura. Benzo, cobrero. Tudo essas coisas."

Dona Yara se relaciona bem com seus vizinhos e não lembra de ter sofrido qualquer tipo de preconceito ou perseguição, por parte de padres ou pastores evangélicos. E não se preocupa em ensinar alguém sobre o ofício de benzer - passar o dom. "Se você ensina antes, você perde todinho poder. A minha falecida mãe sabia muita coisa. Ela faleceu e não me ensinou nada”.

Apesar de nunca ter presenciado sua mãe fazendo um benzimento, Dona Yara relata que ela benzia dente: "Eu sabia, sabia que ela benzia dente, ela derrubava dente com esse benzimento. Eu sei que ela pegava um copo de água com um pedaço de papel [...] fazia aquilo lá [...] e o dente caía." Seu avô materno também era benzedeiro.

A conversa vai se encerrando. Dona Yara fala um pouco sobre os tipos de benzimento e de pessoas que a procuram.

Benzimento de adulto eu quase já não faço, eu gosto mais de criança. Mas se uma pessoa chega e pede pra mim, eu não digo não. Mas eu prefiro mais criança, certo. Mas se precisar, se eu vejo que precise e dá pra fazer, eu faço. Mas pra mim só é mais é bicha, susto, peito aberto, rasgadura. Tem pessoas que vem pedir para arrumar marido, mas eu não faço. Esse negócio de mexer com marido dos outros, essas coisas eu nunca eu fiz. Já 
pediram bastante pra pegá marido dos outros. Eu não faço, já digo que não. Às vezes tem pessoa assim que não gosta. Tem pessoa que não gosta mas eu não faço, não adianta."

Vamos nos despedindo. Passamos os olhos sobre a mesa onde ficam algumas imagens, uma fotografia da Santa Ceia, uma imagem de Nossa Senhora Aparecida. "Eu ganhei essa imagem da minha filha que foi pra Nossa Senhora Aparecida, me trouxe de presente. Mas, o que eu tenho mais fé, mesmo, é nosso pai Oxalá, e no meu santo.”

Referênciais

BLOCH, Marc. Os Reis Taumaturgos: o caráter sobrenatural do poder régio, França e Inglaterra. São Paulo : Companhia das Letras, 1993.

CARVALHO, Antônio C. D. de. Feiticeiros, burlões e mistificadores. São Paulo : Ed. Unesp, 2005.

CHARTIER, R. A história cultural: entre práticas e representações. Lisboa : Difel/Bertrand Brasil, 1990.

FENELON, D. R. Cultura e história social: historiografia e pesquisa. Projeto História, São Paulo, n. 10, dez. 1993.

GINZBURG, Carlo. O Queijo e os vermes: o cotidiano e as idéias de um moleiro perseguido pela inquisição. São Paulo Companhia das Letras, 1987.

Os andarilhos do bem: feitiçaria e cultos agrários nos sécs XVI e XVII. São Paulo : Companhia das Letras, 1988.

História Noturna. Decifrando o sabá. São Paulo : Companhia das Letras, 1991.

HALL, Stuart. Notas sobre la desconstrución de lo popular. História popular y teoria socialista. Barcelona : Editora Crítica/Grijalbo, 1984. p. 93-110.

LÉVI-STRAUSS, C. Antropologia estrutural. Rio de Janeiro : Tempo Brasileiro, 1985

MAUSS, M; HUPERT, H. Esboço de uma teoria geral da magia. São Paulo : Edusp, 1974.

MONTERO, Paula. Magia e pensamento mágico. Ed. Ática : São Paulo, 1986. 
OLIVEIRA Elda Rizzo de. O que é Medicina Popular. São Paulo, Brasiliense, 1984.

SOUZA, Laura de Mello e. O diabo e a terra de Santa Cruz. Feitiçaria e religiosidade popular no Brasil Colonial. São Paulo : Companhia das Letras, 1986.

THOMPSON, E. P. Costumes em comum: estudos sobre a cultura popular tradicional. São Paulo : Companhia das Letras, 1998.

Recebido: $21 / 05 / 2012$

Received: 05/21/2011

Aprovado: 02/07/2012

Approved: 07/02/2012 